\title{
A case of dermatomyositis in a patient with central core disease: unusual association with autoimmunity and genetic muscle disease
}

\author{
Min Jung Kim ${ }^{1 \dagger}$, Mi Hyeon $\mathrm{Kim}^{2 \dagger}$, Sung-Hye Park ${ }^{3}$ and Yeong Wook Song ${ }^{2,4^{*}}$ (D)
}

\begin{abstract}
Background: Dermatomyositis is an inflammatory muscle disease caused by immune-mediated muscle injury, and central core disease (CCD) is a congenital myopathy associated with disturbed intracellular calcium homeostasis and excitation-contraction coupling. To date, CCD has not been reported to have autoantibodies or coexist with inflammatory myopathy.

Case presentation: Here, we described the case of a 25 -year-old woman who had progressive proximal muscle weakness, myalgia, pruritic macular rash, skin ulcers, and calcinosis. Dermatomyositis was initially suspected based on the clinical symptoms accompanied by elevated muscle enzyme levels, electromyography abnormalities, and a positive antinuclear antibody test. However, the patient's muscle biopsy revealed the characteristic findings of both dermatomyositis and CCD, suggesting that dermatomyositis occurred in this patient with previously asymptomatic CCD. The patient did not have any pathogenic gene mutations associated with congenital myopathy, including RYR1 and SEPN1 in targeted next-generation sequencing. She received high-dose glucocorticoid therapy and azathioprine with a significant improvement in muscle strength.

Conclusions: We present a case of rare coexistence of dermatomyositis and CCD. Clinicians should be aware that patients with CCD may have inflammatory myopathy that responds well to immunosuppressive therapy.
\end{abstract}

Keywords: Dermatomyositis, Central core disease, Congenital myopathy

\section{Background}

Dermatomyositis and central core disease (CCD) are well-recognized, distinct muscle diseases. Dermatomyositis is an autoimmune inflammatory myopathy associated with progressive proximal muscle weakness, a characteristic rash and extramuscular manifestations [1]. CCD is a

\footnotetext{
* Correspondence: ysong@snu.ac.kr

${ }^{+}$Min Jung Kim and Mi Hyeon Kim contributed equally to this work.

2Division of Rheumatology, Department of Internal Medicine, Seoul National University Hospital, Daehak-ro, Jongno-gu, Seoul 03080, South Korea

${ }^{4}$ Medical Research Center, Institute of Human-Environment Interface Biology, Seoul, South Korea

Full list of author information is available at the end of the article
}

congenital myopathy characterized by the early onset of hypotonia, predominantly proximal muscle weakness and histopathological features of focally reduced oxidative enzyme activity seen as the central core. Congenital dislocation of the hips and scoliosis and foot deformities are common in CCD [2]. CCD is mainly due to dominant mutations in the ryanodine receptor 1 (RYR1) gene, which encodes channel proteins involved in skeletal muscle calcium homeostasis and excitation-contraction coupling (ECC) [3]. The severity of muscle weakness in patients with CCD due to dominant RYR1 mutation is usually mild; most patients with CCD achieve independent ambulation

C C The Author(s). 2021 Open Access This article is licensed under a Creative Commons Attribution 4.0 International License, which permits use, sharing, adaptation, distribution and reproduction in any medium or format, as long as you give appropriate credit to the original author(s) and the source, provide a link to the Creative Commons licence, and indicate if changes were made. The images or other third party material in this article are included in the article's Creative Commons licence, unless indicated otherwise in a credit line to the material. If material is not included in the article's Creative Commons licence and your intended use is not permitted by statutory regulation or exceeds the permitted use, you will need to obtain permission directly from the copyright holder. To view a copy of this licence, visit http://creativecommons.org/licenses/by/4.0/. The Creative Commons Public Domain Dedication waiver (http://creativecommons.org/publicdomain/zero/1.0/) applies to the data made available in this article, unless otherwise stated in a credit line to the data. 
with slow progression, and are clinically asymptomatic even in about $40 \%$ of patients with histological signs of disease $[4,5]$.

There seems to be little relationship between inflammatory myopathy and genetic muscle diseases. However, there have been descriptions of patients with muscular dystrophy and myositis-specific autoantibodies [6]. The presence of autoantibodies may exacerbate muscle inflammation due to the high levels of autoantigens expressed by regenerating muscle cells, leading to overlapping inflammatory myopathy. To date, congenital myopathy has not been reported to have autoantibodies or coexist with inflammatory myopathy.

Here, we report a rare case of dermatomyositis coexisting with $C C D$ presenting as severe progressive proximal muscle weakness and a skin rash with ulcerations and calcinosis.

\section{Case presentation}

A previously healthy 25-year-old Korean woman had a two-month history of progressive proximal muscle weakness. She had myalgia, fever, severe alopecia and a pruritic macular rash over her face, hand dorsum, upper anterior chest and upper back. She had difficulty in sitting up and could only move around using a wheelchair. She had no hypotonia, feeding difficulty, dysarthria, motor developmental delay, or orthopaedic abnormalities in infancy or early childhood. Her family history was unremarkable.

On physical examination, her vital signs were stable, and her body mass index was $21.8 \mathrm{~kg} / \mathrm{m}^{2}$ (height $156 \mathrm{~cm}$, weight $53 \mathrm{~kg}$ ). Her bilateral muscle strength was grade $4 / 5$ at neck flexion, $4 / 5$ at shoulder abduction, $4 / 5$ in wrist flexion, $4 / 5$ in hand grip, $2 / 5$ in the proximal hips, and $4 / 5$ in ankle dorsiflexion. She had normal reflexes of the biceps brachii, patella, and ankle. Facial erythema involving the nasolabial folds and an erythematous rash on the upper back and anterior chest wall compatible with $\mathrm{V}$-neck sign and shawl sign were observed. Skin ulcers were seen on the hand knuckles, right elbow and lateral aspect of the right thigh (Fig. 1). She had widespread, palpable soft tissue thickening of the bilateral thigh and upper arm with tenderness, which turned out to be calcification. The laboratory results were as follows: white blood cell count, $6440 / \mathrm{mm}^{3}$ with lymphopenia (lymphocyte $322 / \mathrm{mm}^{3}$ ); haemoglobin, $9.1 \mathrm{~g} / \mathrm{dL}$; platelet, $148,000 / \mathrm{mm}^{3}$; erythrocyte sedimentation rate (ESR), 72 $\mathrm{mm} / \mathrm{hr}$.; C-reactive protein (CRP), $0.44 \mathrm{mg} / \mathrm{dL}$; aspartate aminotransferase (AST), 95 (1-40) IU/L; alanine aminotransferase (ALT), 30 (1-40) IU/L; creatine kinase (CK), 128 (20-270) IU/L; lactate dehydrogenase (LDH), 553 (100-225) g/dL; myoglobin, 47.1 (0-106) ng/mL; aldolase, $10.8(0-7.6) \mathrm{U} / \mathrm{L} ; \mathrm{C} 3,83(83-193) \mathrm{mg} / \mathrm{dL}$; and C4, $19(15-57) \mathrm{mg} / \mathrm{dL}$. The antinuclear antibody test was positive and showed a homogeneous pattern at a 1:160 dilution, but the anti-dsDNA, anti-Sm, anti-Ro, anti-La, anti-Scl-70, anti-centromere, anti-U1 ribonucleoprotein, anti-phospholipid, and anti-Jo-1 antibody tests were all negative. Magnetic resonance imaging (MRI) of the thigh showed symmetric diffuse muscle signal changes with an enhanced T2 signal and diffuse patchy contrast enhancement involving both the anterior and posterior compartments of the thigh (Fig. 2). Her radiographs of shoulders and pelvis showed extensive, plaque-like soft tissue calcification of both hips, thighs and upper arms. Electromyography (EMG) showed fibrillations, positive sharp waves (PSWs), increased amplitudes of motor unit action potential (MUAP) and reduced interference pattern in the biceps. In the EMG of the tibialis and gastrocnemius muscles, fibrillations, PSWs, small and polyphasic MUAPs, and reduced interference pattern were identified. In contrast, the nerve conduction study revealed normal responses. A muscle biopsy of the right vastus lateralis demonstrated many degenerating and regenerating muscle fibers and perifascicular atrophy with moderate infiltration of inflammatory cells in the endomysial and perivascular areas, consistent with dermatomyositis. However, enzyme histochemical analysis showed centrally placed cores in the type I myofibers with nicotinamide adenine dinucleotide dehydrogenase (NADH)
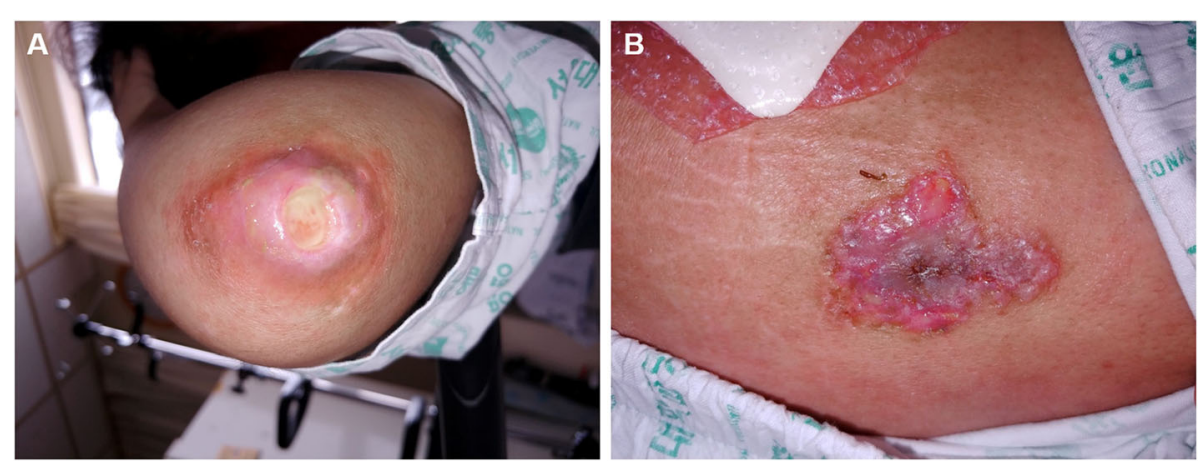

Fig. 1 Skin ulcerations on $\mathbf{A}$ the elbow and $\mathbf{B}$ thigh 

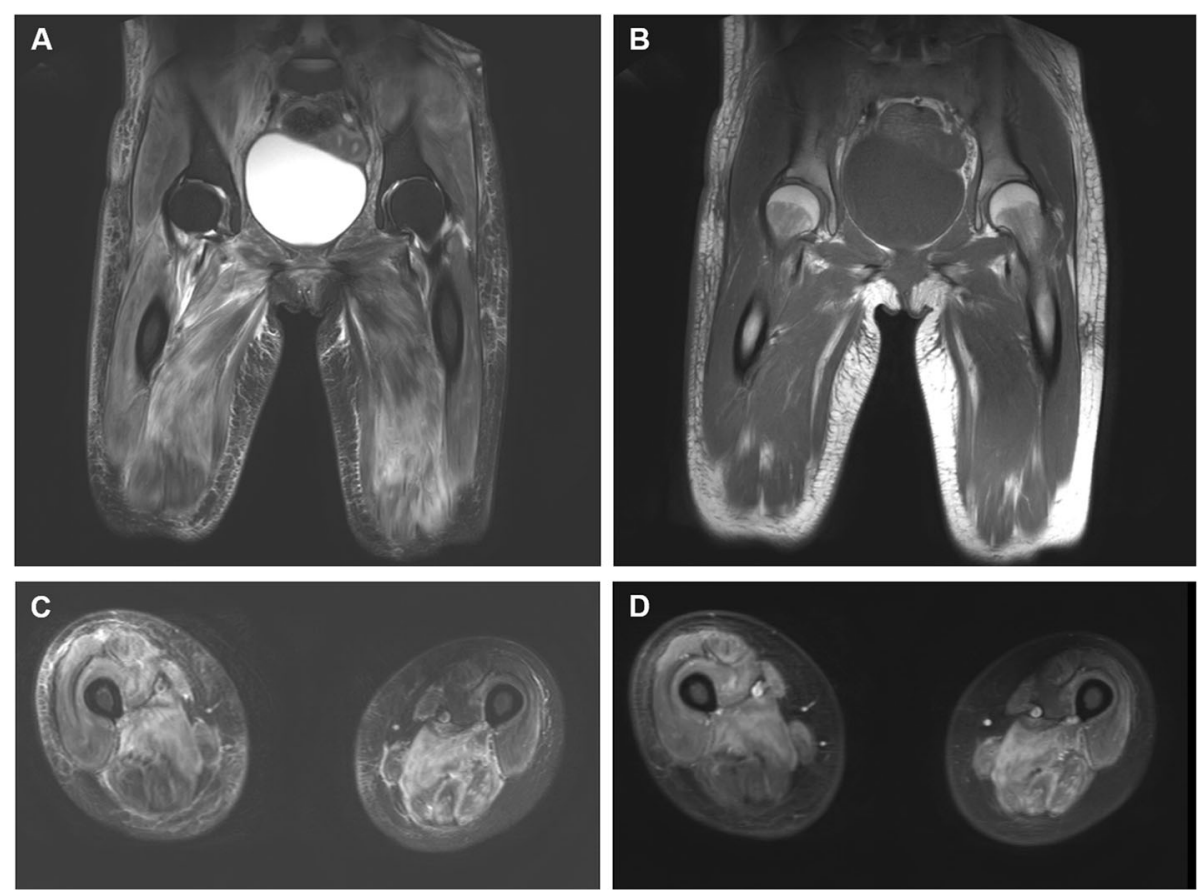

Fig. 2 Magnetic resonance imaging of the thigh. Coronal images show $\mathbf{A}$ increased T2 signal intensity and $\mathbf{B}$ normal T1 signal intensity in the pelvis and proximal thigh. C Axial T2-weighted and $\mathbf{D}$ gadolinium-enhanced T1-weighted image shows symmetric diffuse muscle edema and inflammation with relative preservation in the left anterior compartment of the thigh

and succinate dehydrogenase (SDH) staining, suggesting CCD (Fig. 3a). Electron microscopy showed both tubuloreticular bodies in the endothelial cells and disorganized myofilaments with scattered short Z-bands and structured central cores in the muscle fibers, findings that suggested a diagnosis of CCD with superimposed dermatomyositis (Fig. 3c and d). Computed tomography of the chest and abdomen showed no evidence of interstitial lung disease or malignancy. The echocardiography was normal. The patient had no pathogenic mutations in the genes associated with congenital myopathy, including RYR1, SEPN1, ACTA1, AGRN, BIN1, CFL2, CHAT, CHRN A1, CHRNB1, CHRND, CHRNE, COLQ, DNM2, DOK2, GFPT1, IGHMBP2, KBTBD13, KLHL40, LAMB2, MTM1, MUSK, MYH7, RAPSN, SLC5A7, SMN1, TNNT1, TPM2, TPM3 and TTN, in hybridization capture-based nextgeneration sequencing. However, she had a heterozygous mutation in the NEB gene of c.8318G > A (p.Arg2773Gln), which is considered a variant of uncertain significance. Parental genetic testing was negative.

The patient received intravenous methylprednisolone at $100 \mathrm{mg}$ daily for 3 days, followed by oral prednisolone at $25 \mathrm{mg}$ twice a day and azathioprine at $50 \mathrm{mg}$ daily. Additionally, she started regular physiotherapy and rehabilitation to maintain mobility. One month later, the patient had a significant improvement in muscle strength with a decrease in muscle enzyme levels (Fig. 4). The muscle strength for hip flexion improved to grade
$4 / 5$ after 1 month of treatment and to grade $5 / 5$ (normal) after 3 months of treatment. The patient did not complain of respiratory symptoms and had no abnormal findings on chest radiographs after 1 year of follow-up. Currently, the patient is able to walk on her own, and is taking $7.5 \mathrm{mg} /$ day of prednisolone and $100 \mathrm{mg} /$ day of azathioprine.

\section{Discussion}

Dermatomyositis is an immune-mediated inflammatory muscle disease characterized by proximal muscle weakness. In contrast, CCD shows the disruption of intracellular muscle calcium homeostasis and ECC by genetic mutations, and is associated with typically proximal muscle weakness. We described a patient with severe, debilitating proximal muscle weakness, elevated muscle enzyme levels, myopathic EMG abnormalities, skin rash, and calcinosis who was clinically diagnosed with dermatomyositis. However, her muscle biopsy revealed the characteristic findings of both dermatomyositis and CCD, suggesting that dermatomyositis occurred in this CCD patient who had no previous symptoms. The coexistence of dermatomyositis and CCD may be a coincidence, but it may also suggest a link between autoimmunity and genetic muscle disease that affects intracellular calcium homeostasis.

The congenital myopathies are a group of early-onset, non-dystrophic genetic neuromuscular diseases with 


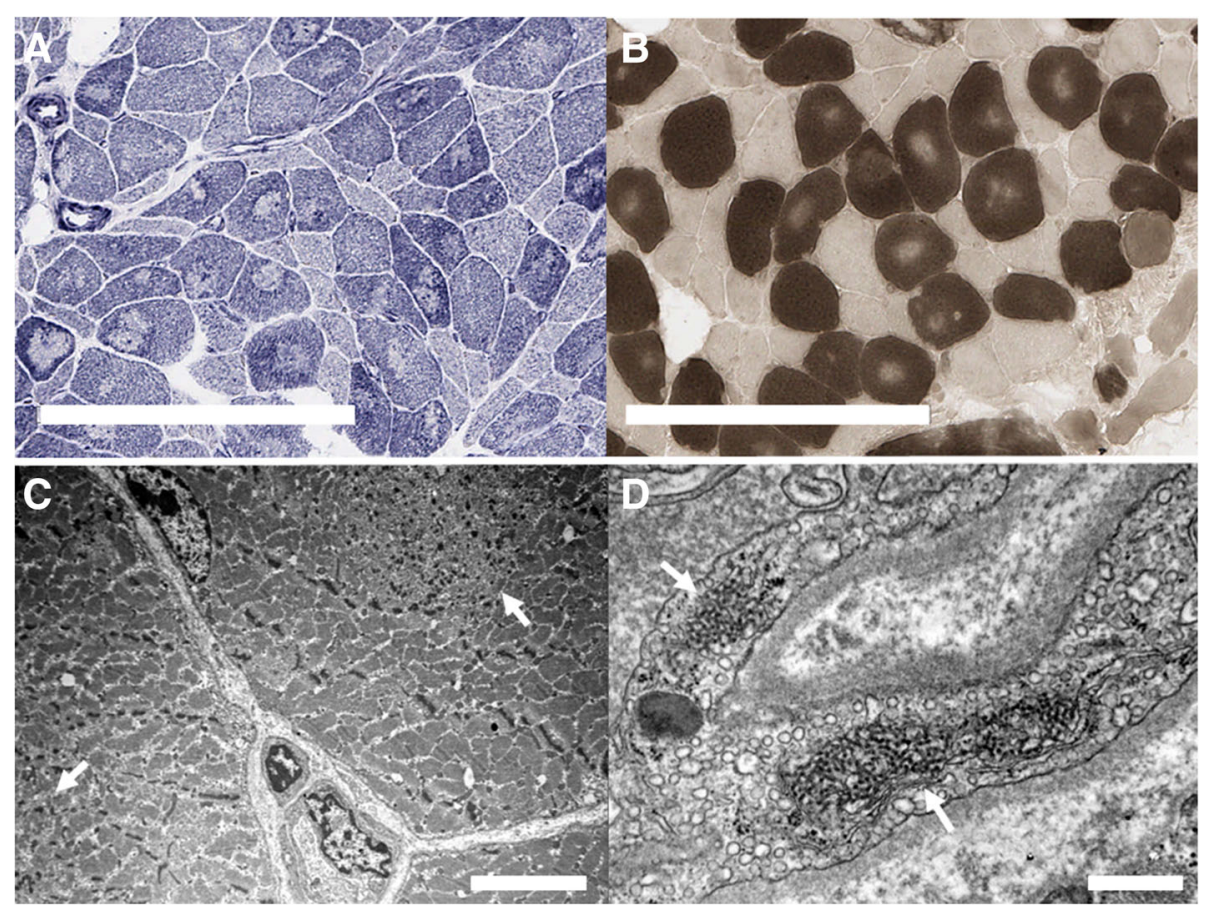

Fig. 3 Histological findings in a muscle biopsy specimen obtained from the vastus lateralis. A NADH-tetrazolium reductase stain shows irregularly outlined central cores in the type I myofibers (bar: $200 \mu \mathrm{m}$ ). B ATPase pH 4.3 shows pale central cores in the type I myofibers (bar: $200 \mu \mathrm{m}$ ). Electron microscopy (adenyl acetate and lead citrate stain) shows $\mathbf{C}$ a structured central core composed of randomly scattered short Z-bands and fine filaments (arrow) (bar: $5 \mu \mathrm{m}$ ), and $\mathbf{D}$ two tubuloreticular bodies (arrows) in the endothelial cells (bar: $500 \mathrm{~nm}$ )

characteristic muscle biopsy findings, consisting of CCD, multi-minicore disease $(\mathrm{MmD})$, centronuclear myopathy and nemaline myopathy [2]. Congenital myopathies have been attributed to mutations in genes encoding proteins implicated in skeletal muscle calcium homeostasis, ECC, thin-thick filament assembly, and their interactions [2]. For a muscle contraction to occur, calcium release from the sarcoplasmic reticulum (SR) to the sarcoplasm leads to sarcomere shortening through interactions between the thin and thick filaments driven by adenosine triphosphate (ATP) [7]. This ECC is terminated by calcium reuptake by the SR. Therefore, continuous calcium leak to the sarcoplasm and disturbed ECC causes muscle weakness to develop in congenital myopathies, especially CCD. Histologically, CCD is characterized by centrally located, well-demarcated cores of diminished or absent oxidative enzyme activity in the muscle fibers. Type I fiber predominance and atrophy are common in CCD [8]. CK levels may be normal or mildly elevated. Selective muscle involvement with increased T1 signal seen on muscle MRI depends on the subset of congenital myopathy, which can also be distinguished from inflammatory myopathy [9].

CCD is closely associated with dominant RYR1 mutations, implying that the typical central cores on muscle biopsy are highly suggestive of RYR1 defect [2]. Previously, RYR1 mutations was reported to be responsible for $47-67 \%$ of patients with CCD, suggesting that the disease is genetically heterogeneous [10-12]. However, the mutation screening performed in these studies was limited to the three hot spots of the RYR1 gene, especially the $\mathrm{C}$-terminal region most relevant to CCD. In contrast, a previous study covering the full coding regions of the $R Y R 1$ gene in a cohort of Japanese CCD patients showed that RYR1 mutations occur in $93 \%$ of CCD patients [12]. Of note, functional studies are needed when mutations are detected in the RYR1 and $N E B$ genes which are associated with congenital myopathies, as variants of uncertain significance are common in these genes due to their large size [13]. In addition, mutations in the RYR1-binding proteins, FKBP12 and CACNA1S, identified as directly participating in ECC, may also contribute to the RYR1 channel dysfunction [14]. Mutations have been identified in CACNA1S in patients with malignant hyperthermia and primary periodic paralysis $[12,15]$. Thus, RYR1-binding proteins may also need to be studied in more detail in patients with CCD.

Targeted next-generation sequencing did not detect any genetic mutations related to congenital myopathy, including $R Y R 1$, in our patient. However, the typical central cores were clearly revealed by NADH and SDH staining of a majority of muscle fibers in the patient. In addition, ultrastructually, disarray of the myofilaments with scattered short Z-bands and structured central 


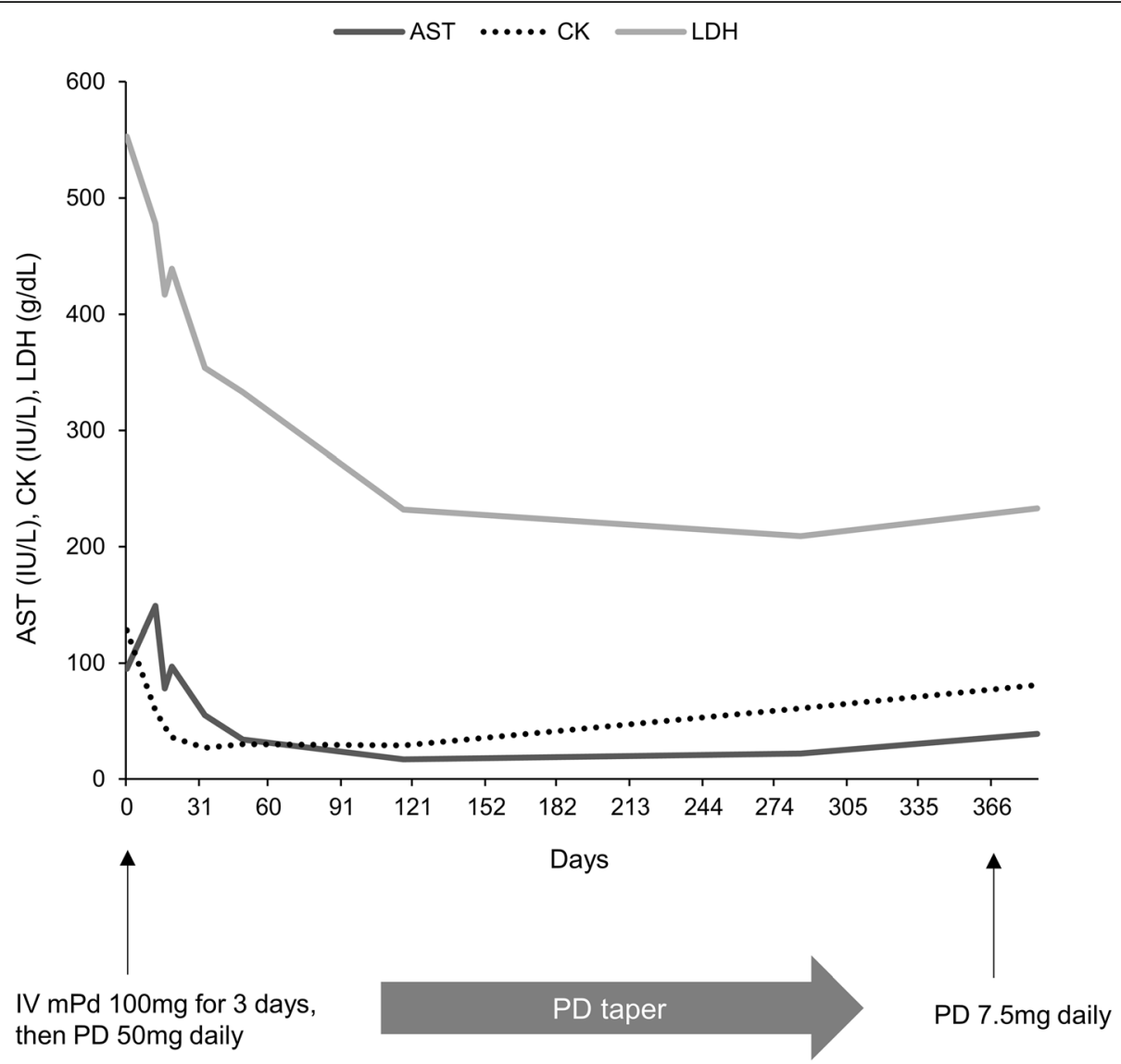

Fig. 4 Changes in serum levels of skeletal muscle enzymes and daily doses of glucocorticoid during the follow-up period. AST, aspartate aminotransferase, CK, creatine kinase, LDH, lactate dehydrogenase, $\mathrm{PD}$, prednisolone, $\mathrm{mPd}$, methylprednisolone

cores was observed, which is highly suggestive of CCD. Inclusion body myositis can show mitochondrial abnormalities such as cytochrome c oxidase (COX) deficiency in muscle fibers, but COX-negative/SDH-positive staining is seen throughout the muscle fibers rather than in the central region [16]. Histological signs of deficiency in oxidative enzyme activities in dermatomyositis and polymyositis have not been shown in previous reports. Patients with CCD without identifiable RYR1 mutations may have mutations in unknown genes or RYR1 mutations may still exist in unexamined regions such as promoter region, introns and casual copy number variations.

Several muscular dystrophies, such as facioscapulohumeral dystrophy and limb-girdle muscular dystrophy, show muscle regeneration and inflammatory cell infiltrates in muscle fibers, similar to inflammatory myopathy [17]. Additionally, myositis-specific autoantibodies such as anti-Jo-1 and anti-Mi2 were found in patients with muscular dystrophy [6]. Based on these findings, autoantigens may be expressed in the regenerating muscle fibers of muscular dystrophy, triggering an autoimmune process and overlapping with inflammatory myopathy [18]. In contrast, congenital myopathies rarely show muscle regeneration, and may lead to very low levels of myositis autoantigen expression. Instead, aberrant intracellular calcium homeostasis in congenital myopathy may affect the immune system. For instance, increased $\mathrm{T}$ cell receptor-mediated calcium influx in lupus $\mathrm{T}$ cells contributes to $\mathrm{T}$ cell activation by inducing the activation of calcineurin [19]. RYR1, a calcium-release channel protein associated with CCD, is expressed preferentially in skeletal muscle, but is also expressed in B cells and dendritic cells. RYR1-mediated intracellular calcium influx in B cells and dendritic cells may cause their activation and the release of pro-inflammatory cytokines [20-22]. Interestingly, dermatomyositis is characterized by abnormal humoral immunity related to B cell activation producing autoantibodies. Previous studies have reported rare cases of muscular dystrophy coexisting with autoantibodies. However, to the best of our knowledge, this is the first report of inflammatory myopathy coexisting with congenital myopathy and the first report of autoantibodies found in the patient with congenital myopathy. Further 
studies on autoantibodies in CCD patients may be needed when dermatomyositis or other autoimmune disease is suspected in patients with CCD.

The management of congenital myopathies is mainly supportive [23], whereas inflammatory myopathies respond well to treatment with glucocorticoid and immunosuppressive agents. Immunosuppressive therapy was also effective in improving muscle strength in the present case with dermatomyositis coexisting with CCD. Therefore, inflammatory myopathy should be suspected in a patient with congenital myopathy if he or she presents with a sudden deterioration in muscle strength, particularly along with extramuscular symptoms or the presence of autoantibodies. We suggest that a muscle biopsy or MRI should be performed to evaluate for overlapping inflammatory myopathy.

In summary, we reported a rare case of the coexistence of dermatomyositis and CCD. Clinicians should be aware that patients with CCD could have inflammatory myopathy, which responds well to immunosuppressive therapy. Testing for autoantibodies, and muscle MRI or muscle biopsy may help distinguish between inflammatory myopathy and underlying genetic muscle diseases. Further research may be needed to decipher the association between autoimmunity and congenital myopathyassociated intracellular calcium homeostasis.

\section{Abbreviations}

ALT: Alanine transaminase; AST: Aspartate transaminase; ATP: Adenosine triphosphate; CCD: Central core disease; CK: Creatine kinase; COX: Cytochrome c oxidase; CRP: C-reactive protein; ECC: Excitation-contracture coupling; EMG: Electromyography; ESR: Erythrocyte sedimentation rate; LDH: Lactate dehydrogenase; MmD: Multi-minicore disease; MRI: Magnetic resonance imaging; MUAP: Motor unit action potential; NADH: Nicotinamide adenine dinucleotide dehydrogenase; PSW: Positive sharp wave; RYR1: Ryanodine receptor 1; SDH: Succinate dehydrogenase; SR: Sarcoplasmic reticulum

\section{Acknowledgments}

Not applicable.

\section{Authors' contributions}

YWS contributed to the study conception and design. Material preparation, data collection and analysis were performed by all listed co-authors. The first draft of the manuscript was written by MJK and MHK, and all authors commented on previous versions of the manuscript. All authors read and approved the final manuscript.

\section{Funding}

This study was funded by a grant from the Ministry of Science, ICT, and Future Planning (NRF-2020M3E5E2037430 to Y-W.S.).

\section{Availability of data and materials}

The datasets used during the current study are available from the corresponding author on reasonable request.

\section{Declarations}

\section{Ethics approval and consent to participate}

The study complied with the Declaration of Helsinki and was approved by the Institutional Review Board of Seoul National University Hospital. Informed consent was obtained from the patient.

\section{Consent for publication}

Informed written consent for patient information and images to be published was obtained from the patient.

\section{Competing interests}

The authors declare that they have no competing interests.

\section{Author details}

${ }^{1}$ Division of Rheumatology, Department of Internal Medicine, Seoul Metropolitan Government-Seoul National University Hospital Boramae Medical Center, Seoul, South Korea. 'Division of Rheumatology, Department of Internal Medicine, Seoul National University Hospital, Daehak-ro, Jongno-gu, Seoul 03080, South Korea. ${ }^{3}$ Department of Pathology, Seoul National University College of Medicine, Seoul, South Korea. ${ }^{4}$ Medical Research Center, Institute of Human-Environment Interface Biology, Seoul, South Korea.

Received: 12 January 2021 Accepted: 1 May 2021

Published online: 30 June 2021

\section{References}

1. Dalakas MC, Hohlfeld R. Polymyositis and dermatomyositis. Lancet. 2003;362: 971-82.

2. Jungbluth $H$, Treves S, Zorzato F, Sarkozy A, Ochala J, Sewry C, et al. Congenital myopathies: disorders of excitation-contraction coupling and muscle contraction. Nat Rev Neurol. 2018:14:151.

3. Jungbluth $H$, Sewry CA. Muntoni F, editors. Core myopathies Semin Pediatr Neurol. 2011:18:239-49.

4. Colombo I, Scoto M, Manzur AY, Robb SA, Maggi L, Gowda V, et al. Congenital myopathies: natural history of a large pediatric cohort. Neurology. 2015;84:28-35.

5. Shuaib A, Paasuke RT, Brownell KW. Central core disease. Clinical features in 13 patients. Medicine (Baltimore). 1987:66:389-96.

6. Mammen AL, Casciola-Rosen L, Christopher-Stine L, Lloyd TE, Wagner KR. Myositis-specific autoantibodies are specific for myositis compared to genetic muscle disease. Neurol Neuroimmunol Neuroinflamm. 2015;2:e172.

7. Gordon AM, Homsher E, Regnier M. Regulation of contraction in striated muscle. Physiol Rev. 2000;80:853-924.

8. Sato I, Wu S, Ibarra MC, Hayashi YK, Fujita H, Tojo M, et al. Congenital neuromuscular disease with uniform type 1 fiber and RYR1 mutation. Neurology. 2008;70:114-22.

9. Jungbluth $H$, Davis MR, Müller C, Counsell S, Allsop J, Chattopadhyay $A$, et al. Magnetic resonance imaging of muscle in congenital myopathies associated with RYR1 mutations. Neuromuscul Disord. 2004;14:785-90

10. Shepherd S, Ellis F, Halsall J, Hopkins P, Robinson R. RYR1 mutations in UK central core disease patients: more than just the C-terminal transmembrane region of the RYR1 gene. J Med Genet. 2004:41:e33.

11. Davis MR, Haan $E$, Jungbluth $H$, Sewry $C$, North $K$, Muntoni F, et al. Principal mutation hotspot for central core disease and related myopathies in the Cterminal transmembrane region of the RYR1 gene. Neuromuscul Disord. 2003;13:151-7.

12. Wu S, Ibarra MC, Malicdan MC, Murayama K, Ichihara Y, Kikuchi H, et al. Central core disease is due to RYR1 mutations in more than $90 \%$ of patients. Brain. 2006:129:1470-80.

13. North KN, Wang $\mathrm{CH}$, Clarke $\mathrm{N}$, Jungbluth $\mathrm{H}$, Vainzof $\mathrm{M}$, Dowling JJ, et al. Approach to the diagnosis of congenital myopathies. Neuromuscul Disord. 2014;24:97-116

14. Witherspoon JW, Meilleur KG. Review of RyR1 pathway and associated pathomechanisms. Acta Neuropathol Commun. 2016;4:121

15. Luo S, Xu M, Sun J, Qiao K, Song J, Cai S, et al. Identification of gene mutations in patients with primary periodic paralysis using targeted nextgeneration sequencing. BMC Neurol. 2019;19:92.

16. Hilton-Jones D, Brady S. Diagnostic criteria for inclusion body myositis. Intern Med. 2016;280:52-62.

17. Choi J-H, Park Y-E, Kim S-I, Kim J-I, Lee C-H, Park K-H, et al. Differential immunohistological features of inflammatory myopathies and dysferlinopathy. J Korean Med Sci. 2009:24:1015-23.

18. Casciola-Rosen L, Nagaraju K, Plotz P, Wang K, Levine S, Gabrielson E, et al. Enhanced autoantigen expression in regenerating muscle cells in idiopathic inflammatory myopathy. J Exp Med. 2005;201:591-601. 
19. Katsuyama T, Tsokos GC, Moulton VR. Aberrant T cell signaling and subsets in systemic lupus erythematosus. Front Immunol. 2018;9:1088.

20. Kushnir A, Santulli G, Reiken SR, Coromilas E, Godfrey SJ, Brunjes DL, et al. Ryanodine receptor calcium leak in circulating B-lymphocytes as a biomarker in heart failure. Circulation. 2018;138:1144-54.

21. Vukcevic M, Zorzato F, Keck S, Tsakiris DA, Keiser J, Maizels RM, et al. Gain of function in the immune system caused by a ryanodine receptor 1 mutation. J Cell Sci. 2013;126:3485-92.

22. Girard T, Cavagna D, Padovan E, Spagnoli G, Urwyler A, Zorzato F, et al. Blymphocytes from malignant hyperthermia-susceptible patients have an increased sensitivity to skeletal muscle ryanodine receptor activators. J Bio Chem. 2001;276:48077-82.

23. Wang CH, Dowling JJ, North K, Schroth MK, Sejersen T, Shapiro F, et al. Consensus statement on standard of care for congenital myopathies. J Child Neurol. 2012:27:363-82

\section{Publisher's Note}

Springer Nature remains neutral with regard to jurisdictional claims in published maps and institutional affiliations.

Ready to submit your research? Choose BMC and benefit from:

- fast, convenient online submission

- thorough peer review by experienced researchers in your field

- rapid publication on acceptance

- support for research data, including large and complex data types

- gold Open Access which fosters wider collaboration and increased citations

- maximum visibility for your research: over $100 \mathrm{M}$ website views per year

At BMC, research is always in progress.

Learn more biomedcentral.com/submissions 